\title{
Cognitive Styles and Accounting Information Navigation: A Preliminary Investigation
}

\author{
Thanachart Ritbumroong \\ Thammasat Business School \\ Thammasat University \\ Thailand
}

\author{
Somchai Supattarakul \\ Thammasat Business School \\ Thammasat University \\ Thailand
}

\author{
Uthai Tanlamai \\ Chulalongkorn Business School \\ Chulalongkorn University \\ Thailand
}

\begin{abstract}
Interactive information visualization is a new research direction in the area of accounting information systems dealing with the use of technology to interactively visually represent data to enhance an individual's ability to acquire and use knowledge. One of important topics in this line of research is the information selection and navigation. The present study follows this research direction by attempting to explore the extent to which accounting information is searched and navigated in different patterns of tasks and decision-makers. Following a quasi experiment design, a web application was developed to collect data. Participants were required to perform a task in analyzing ROA data using given financial information of an anonymous fictious firm. The treatment of this study is the navigation strategy. The results of the data analysis have shown that the decision-making performance between two cognitive styles (field-independent and field-dependent) and two navigation strategies (breadth-first and depth-first) was not statistically significantly different. Nevertheless, the time spent in identifying the correct information was found to be significantly different between the two cognitive styles; field-independent and field-dependent. This research is an initial step in investigating the influence of decision-maker characteristics and navigation strategies on the decision-making process. There is still an ample area to further investigate how information technology in information navigation could be benefit in the decision-making process.
\end{abstract}

Keywords-component; cognitive styles, information navigation, accounting information

\section{INTRODUCTION}

The advancement of information technology enhances accounting decision-making by allowing users to effectively interact and handle with a large amount of data. These data were captured by a wide array of accounting information systems; for instance Enterprise Resource Planning (ERP) or Business Intelligence (BI), with the aim to produce valuable information for supporting decision-making. ERP serves as an infrastructure of accounting information systems integrating all business processes together. Data are recorded where a transaction is made. This enables management to trace to an origin of a business transaction. Whereas, BI provides a venue for business users to interactively explore and analyze accounting information acquired from every part of an organization.

With the capability of BI technology, users can access and interact with data visually to support their decision-making. Recently, researchers have paid a significant amount of attention in the area which decision-making can be improved by BI technology. The concept of information visualization was developed to study the use of technology in interactively visually representing data in order to enhance ability to acquire and use knowledge (Card \& Mackinlay, 2009). Previous studies have shown that interactive data visualization could help reduce cognitive load and improve accuracy of decisionmaking. Vessey (1991) found that the decision-making performance can be improved when there is a cognitive fit between the information representation type and the task type. Having reviewed research in this particular area, Dilla et al. (2010) proposed new research directions in the area of accounting information systems by emphasizing the need to further investigate how this interactive information visualization could affect decision-making. They further argued that characteristics of a task and a decision-maker could influence information selection and navigation which, in turn, affects decision-making processes and outcomes.

Little has been known about how this technology could help improve decision-making, especially in the context where accounting information is the primary source of information used to support decision-making. There is a lot of information presented in financial statements to support an individual in making an economic decision. Even though there are various frameworks of financial statement analysis available, financial report users have choices to choose a set of information to support their decision-making process. Nevertheless, users could be easily get lost in a large amount of information. With modern information technologies, information in financial statements can be made interactive. Users can navigate from one point to another effectively. The objectives of this research will are to gain more understanding how an individual navigate through financial statements employing information 
visualization technologies to support a decision-making process. Thus, this study aims to explore effects of decisionmaker characteristics and information navigation strategies on decision-making performance.

In addition, the benefits of this study would also help practitioners in terms of developing a more comprehensive information system utilizing accounting data to support decision-making. Both public and private sectors have adopted BI systems to support decision-making at all level of management. Especially, dashboard is the most popular application in this family of applications. Yigitbasioglu and Velcu (2011) argued that the use of this particular application would help rectify the information overload issue. They further investigated previous studies and identified issues related to the design aspect of these so-called dashboards. Two groups of design features including function and visual were argued to improve decision-making performance. One of many interesting topics to be noted in addition to their work is the issue of information navigation that seems to be under studied. Dilla et al. (2010) also did not find any research linked directly to the topic of information navigation. However, they provided indirect evidence to support their arguments that information navigation is also one important research direction to pursue.

The remainder of this manuscript is organized as follows. The next section provides theoretical background. Consequently, details of research method are provided. And it follows by data analysis and result discussion. Lastly, conclusion and recommendation for future research is discussed.

\section{THEORETICAL BACKGROUND}

Gallistel (1990) defined navigation as “... the process of determining and maintaining a course or trajectory from one place to another ...". Later, Spence (1999) developed a framework for navigation and offered a more specific definition of navigation as "... the creation and interpretation of an internal (mental) model, and its component activities are browsing, modeling, interpretation and the formulation of browsing strategy ...". Given the context of information visualization, information navigation can be defined as the process of maneuvering from one specific piece of information to another specific piece of information. It should be noted that information navigation and information search are different. Information search is defined as the process of collecting and integrating information from different sources to support decision-making process (Schmidt and Spreng 1996). Dilla et al. (2010) argued that information navigation would affect the decision-making outcome. Decision-maker Characteristics and task-characteristics were believed to affect information navigation which, in turns, influences the outcome of decisionmaking. Although the effects of task characteristics on decision-making performance are quite prevalent, only one task is investigated in order to focus on the effects of information navigation and decision-maker characteristics.

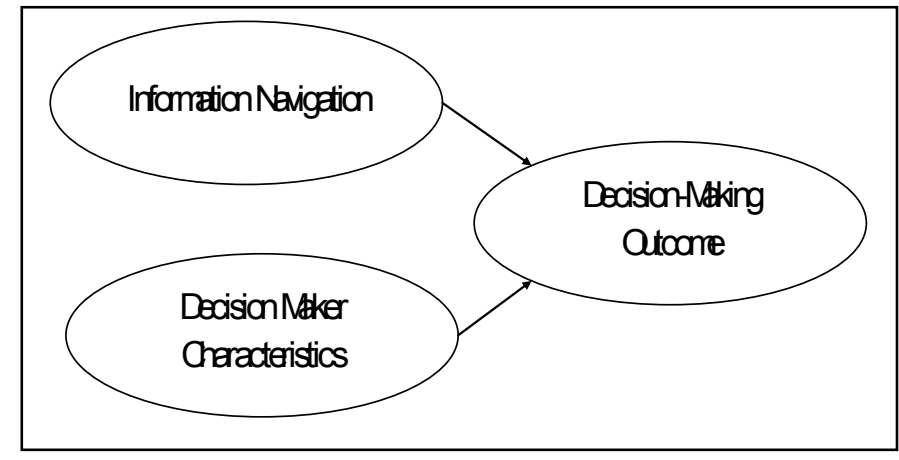

Figure 1. Proposed Research Framework

To explain how information navigation and decision-maker characteristics could affect decision-making outcome as depicted in the figure 1 , the concept of accounting aggregation is employed to help clarify the proposed relationships. Discussions of accounting aggregation can be traced back to the two commonly cited models (Otley and Dias 1982). The first model is information theory proposed by Lev (1969). The model explains how information loss by an aggregation process in financial statements could be measured. Another model is an information-economics approach following the informationstructures theory on evaluating the value of information (Demski 1980; Feltham 1977). In a nutshell, the concept of accounting aggregation concerns with how a level of accounting information details affect decision-making. A brief discussion of this concept will be provided in the following section. In addition, the concept of cognitive styles which deals with individual difference in decision-making will also be discussed.

\section{A. Accounting Aggregation}

Accounting aggregation is a concept concerning with the amount of accounting information detail to be presented or provided. Harvey et al. (1979) stated that the usefulness of accounting information is influenced by the extent to the information is aggregated or summarized. Even though the aggregation may sacrifice some content of information, it could help enhance the relevance of message communicated. They conducted an experiment and found that participants in an investment analysis situation preferred highly-aggregated financial statement information. They further suggested that aggregation decisions should be given consideration in the design of information systems. On the contrary to the study of aggregated accounting information, Ohlson and Penman (1992) argued that the aggregated bottom line numbers such as earnings and book value are insufficient. Alles and Vasarhelyi (2007) also posited that there is a need to reengineer the process of financial reporting with three vital reasons stated; 1 ) capabilities of financial report users, 2) information processing and reporting cost, and 3) the financial reporting process. Consequently, they posted an important question addressing the issue of accounting aggregation. Sophisticated users might prefer disaggregated information to highly condensed information since they can have free choices to convert information into their preferred form or format. This method 
would allow them to make more informed decision as information is relevant to users.

Recently, FASB and IASB established a joint project aiming to develop financial statement presentation ${ }^{1}$. One of main activities is dealing with the issues of aggregating and disaggregating information in financial statements.

\section{B. Cognitive Styles}

As discussed previously, financial statement users seem to prefer a different level of how accounting information should be aggregated. The relationship between accounting aggregation preference and their ability to process information has been suggested by previous research (Otley and Dias 1982; Goldstein and Blackman 1978). There are various cognitive styles proposed by previous studies. Nevertheless, the continuum of field-dependences and field-independence has been widely adopted to investigate an individual's navigation strategy (Ford and Chen 2000; Otley and Dias 1982; Chen and Macredie 2010). Witkin et al. (1974) suggested that a fielddependent person would be dominated by the whole context whereas a field-independent person would be able to separate an item from the context. Mostly, a field-dependent person is perceived to be low analytic while a field-independent person is viewed to be high analytic. Findings from previous research suggested that these two types of cognitive styles prefer a different navigation strategy (Chen and Macredie 2002; Ford and Chen 2001). A field-dependent person tends to prefer the breadth-first strategy while a field-independent person seems to prefer the depth-first structure. Ford and Chen (2001) provided concise explanations of these two navigation strategies and their differences as shown in figure 2 and figure 3 .

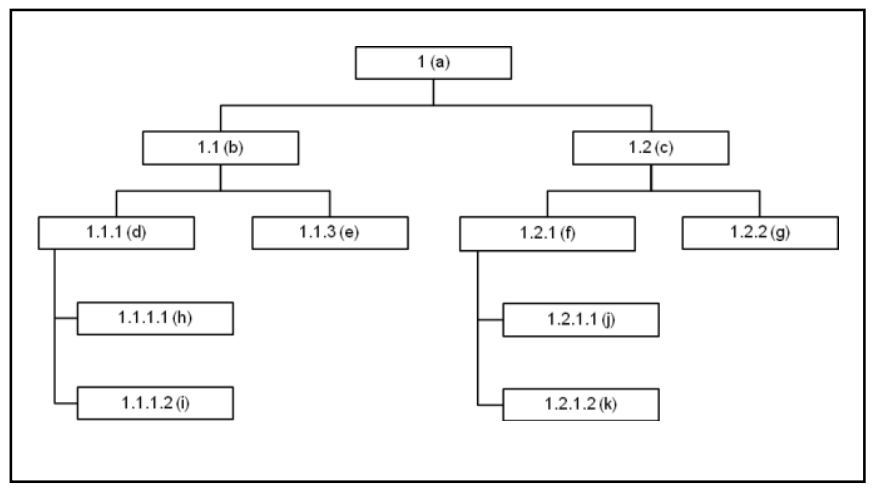

Figure 2. Breadth-First strategy (Ford and Chen 2001)

\footnotetext{
${ }^{1}$ Financial Statement Presentation - Joint Project of the FASB and IASB. It is a project to establish a guideline for firms in the issue relating to presentation of information in the financial statements. The aim of this project is to improve the usefulness of the information presented in statements in order to allow users to make better informed decisions.

http://www.fasb.org/financial_statement_presentation.shtml
}

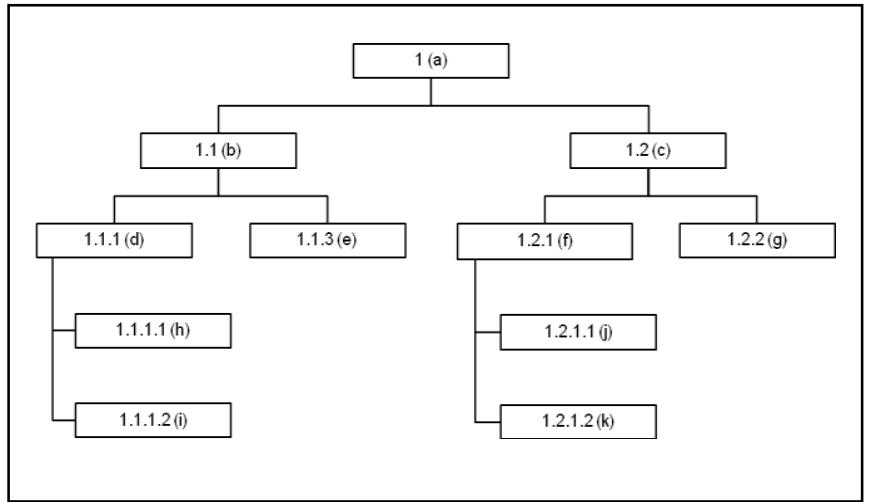

Figure 3. Depth-First strategy (Ford and Chen 2001)

In the breadth-first strategy, an overview of all information is presented and later the next set of information with more details is shown. As illustrated in figure 2, the navigational path start at 1 (a). Then, the next layer of information in the hierarchy is presented $(1.1$ (b) and 1.2 (c)). Later, users will move to the next layer until the end.

In the depth-first strategy illustrated in figure 3, all information in each topic is presented and then before the next topic is later presented in the same manner. Figure 3 shows the sequence of the navigation path. The starting point is 1 (a) and then move to 1.1 (b) and end with (e) for the first topic (1.1.1). After the first topic, the next topic is presented 1.1.3 (e). Users will traverse from the top to the end of each topic until the end.

In the context of accounting information, cognitive styles and navigation strategies would also affect individual decisionmaking performance. The matching patterns between the cognitive styles and navigation strategies were found to improve learning performance (Ford and Chen 2001). Financial statement users whose cognitive style is field independent will perform better when information navigational paths are structured following breadth-first strategy. On the other hand, the depth-first strategy would enhance a field-independent user in making a decision. To investigate the extent to which the cognitive styles and navigation strategies affect the outcomes of decision-making, this study hypothesizes;

Hypothesis 1: $\quad$ Field-dependent users will have better decision-making performance when the breadth-first strategy is employed rather than the depth-first strategy.

Hypothesis 2: $\quad$ Field-independent users will have better decision-making performance when the depth-first strategy is employed rather than the breadth-first strategy.

It is the main aim of this research direction to investigate the effects of information navigation on decision-making. This research is an initial step in investigating the effects of information navigation on decision-making. It is believed that the advancement in technology would help an individual to better consume or utilize accounting information in making an economic decision. The findings from this research will help provide insight into how accounting information system should be designed to aid users in making a better informed decision 


\section{RESEARCH METHOD}

A quasi experiment was employed in this study. It is a research design allowing researchers to assign a treatment to participants (Pedhazur and Schmelkin 1991). This enables researchers to investigate the effects of the given treatments on the participants. This design does not require a laboratory setting like the true experiment research design. It offers more flexibility in the data collection process. In general, participants are not randomly assigned which diminishes the degree of internal validity.

This study follows a quantitative research design concept. Since this study aims to investigate the effects of the pattern between navigation strategies and decision-maker characteristics on the outcomes of decision-making, the treatment of this study is the navigation strategy. The task required subjects to analyze ROA using given financial information of an anonymous fictious firm.

The navigation strategy is the treatment of this study for forming the two groups; the breadth-first and the depth-first. The web application developed in this study randomly assigns these two different navigation strategies. ROA is firstly presented. Next, profit margin and total asset turnover are shown. Net income, sales, and total assets are consequently displayed. Lastly, cost of goods sold, operating expenses, interest expenses, and taxes are presented. For the depth-first strategy, the sequence of ROA information based on DuPont framework is presented. Firstly, ROA is shown. Profit margin and net income follows. Consequently, sales, cost of goods sold, operating expenses, interest expenses, and taxes are displayed. Lastly, total asset turnover and total assets are presented.

\section{A. Measurement}

There are two constructs to be measured in this study; cognitive styles and decision-making performance. This section discusses how these two constructs were measured in the study.

\section{1) Cognitive Styles}

Cognitive styles were measured using the continuum of field-dependences and field-independence (Witkin et al. 1974). Respondents were administered with the online Group Embedded Figures Test (GEFT). The test requires respondents to identify a figure embedded in other different figures to match the figure given. After the end of the test, the time spent for this test is displayed and the participants were asked to record the time spent to the web application. It is used as GEFT scores.

Respondents were classified into two groups using a median split. Respondents with GEFT scores higher than the median are considered to have field-independent tendencies. Other respondents with GEFT scores lower than the median are classified as field-dependent tendencies

\section{2) Decision-making performance}

There are two questions assessing the performance of decision-making. . The first question (Q1) requires respondents to identify the correct information shown in the previous section from 20 items provided. In the second question (Q2), respondents were asked to identify the trend of items selected in the first question. Scores were determined by the correct answers. The total scores of the two questions are 10 .

\section{B. Data Collection}

A web application was developed to collect data for this study. Data collection process is illustrated in figure 7 . The address of the web application was posted and distributed on the internet. Firstly, respondents were introduced to the research and informed about their anonymity. Next, they were asked to complete the Group Embedded Figures Test to identify their cognitive style. Before presented with ROA data, they were randomly assigned with one of the two different navigation strategies; the breadth-first and the depth-first.

DuPont framework was used as a scope of information presented to a respondent because this framework has proven to be parsimonious yet powerful for the evaluation of firm performance (Soliman 2008). Respondents were given with the three years data of this fictious firm with the sequence according to the assigned navigation strategy explained previously. ROA data were manipulated to present the increasing trend over time. This would be used to assess respondents' decision-making performance. After they were presented with all the information, two questions are presented. After the completion of these two questions, they were asked about their demographical data and education background.

\section{DATA ANALYSIS AND RESULTS}

After one month of the data collection, there are 418 persons participating in this research. Given the nature of the quasi experiment, full participation cannot be controlled with this self-administered study. There are three sections in the web application important to the data collection. Table I shows the number of valid responses for the three parts. The first section is the Group Embedded Figures Test used for determining their cognitive styles. There are only 55 participants complete for the test. The Question 1 asks participants to recall what information had been displayed. The total of 98 participants completed this question. And there are 85 participants answering the Question 2. This question requires participants to determine the trend of items they have answered in the Question 1.

TABLE I. NUMBER OF VALID RESPONSES

\begin{tabular}{|l|c|}
\hline \multicolumn{1}{|c|}{ Section } & No. of Valid Responses \\
\hline Group Embedded Figures Test & 55 \\
\hline Question 1 & 98 \\
\hline Question 2 & 85 \\
\hline
\end{tabular}

In order to test how the matched pattern between cognitive styles and navigation strategies could affect the decisionmaking performance, there are only 55 complete valid responses. Nevertheless, other valid responses for the Question 1 and Question 2 were kept for further analyses. The total number of possible responses is 98 participants. 


\section{A. Descriptive Analysis}

Table II shows descriptive statistics of the variables measuring decision-making performance. Out of the total 10 points, participants had average scores of 6.36 (Mean of Q1) and 1.04 (Mean of Q2) in the Question 1 and the Question 2, relatively. The average time they spent in the Question 1 and the Quesiton2 was 1.36 minutes (Mean of Q1Time) and 0.76 minutes (Mean of Q2Time), consequently.

TABLE II. DESCRIPTIVE STATISTICS

\begin{tabular}{|l|c|c|c|}
\hline \multicolumn{1}{|c|}{ Variable } & N & Mean & S.D. \\
\hline Q1 & 98 & 6.36 & 2.50 \\
\hline Q1Time & 98 & 1.37 & 0.77 \\
\hline Q2 & 85 & 1.04 & 1.43 \\
\hline Q2Time & 85 & 0.76 & 0.78 \\
\hline
\end{tabular}

\section{B. Hypothesis Testing}

It was hypothesized that field-dependent users will have better decision-making performance when the breadth-first strategy is employed rather than the depth-first strategy. As shown in Table III, it cannot be concluded that field-dependent users performed differently when assigned with different navigation strategies. Also, Table III provides no evidence to support that field-independent users will have better decisionmaking performance when the depth-first strategy is employed rather than the breadth-first strategy. They appear to perform similarly when different navigation strategies were given.

TABLE III. TABLE TYPE STYLES

\begin{tabular}{|c|c|c|c|c|}
\hline \multirow{2}{*}{$\begin{array}{l}\text { Cognitive } \\
\text { Styles }\end{array}$} & \multirow{2}{*}{$\begin{array}{c}\text { Decision- } \\
\text { Making } \\
\text { Performance }\end{array}$} & \multicolumn{2}{|c|}{ Navigation Strategies } & \multirow{2}{*}{$\begin{array}{c}\begin{array}{c}\text { Mean } \\
\text { Comparison }\end{array} \\
\text { BF-DF } \\
\text { p-value } \\
\text { (t,df) }\end{array}$} \\
\hline & & $\begin{array}{c}\text { BF } \\
\text { (Mean, } \\
\text { SD) }\end{array}$ & $\begin{array}{c}\text { DF } \\
\text { (Mean, } \\
\text { SD) }\end{array}$ & \\
\hline \multirow[t]{4}{*}{$\begin{array}{l}\text { Field } \\
\text { Dependent }\end{array}$} & Q1 & $\begin{array}{c}6.62 \\
(2.181)\end{array}$ & $\begin{array}{c}5.50 \\
(2.739)\end{array}$ & $\begin{array}{c}0.123 \\
(1.165,25)\end{array}$ \\
\hline & Q1Time & $\begin{array}{c}1.54 \\
(0.644)\end{array}$ & $\begin{array}{c}1.45 \\
(0.963)\end{array}$ & $\begin{array}{c}0.385 \\
(0.297,25)\end{array}$ \\
\hline & Q2 & $\begin{array}{c}1.31 \\
(1.316)\end{array}$ & $\begin{array}{c}0.71 \\
(0.914)\end{array}$ & $\begin{array}{c}0.092 \\
(1.370,25)\end{array}$ \\
\hline & Q2Time & $\begin{array}{c}0.64 \\
(0.464)\end{array}$ & $\begin{array}{c}0.57 \\
(0.356)\end{array}$ & $\begin{array}{c}0.661 \\
(0.445,23)\end{array}$ \\
\hline \multirow[t]{4}{*}{$\begin{array}{l}\text { Field } \\
\text { Independent }\end{array}$} & Q1 & $\begin{array}{c}6.62 \\
(2.181)\end{array}$ & $\begin{array}{c}5.50 \\
(2.739)\end{array}$ & $\begin{array}{c}0.177 \\
(0.947,26)\end{array}$ \\
\hline & Q1Time & $\begin{array}{c}1.22 \\
(0.308)\end{array}$ & $\begin{array}{c}1.01 \\
(0.513)\end{array}$ & $\begin{array}{c}0.122 \\
(1.193,26)\end{array}$ \\
\hline & Q2 & $\begin{array}{c}1.30 \\
(2.058)\end{array}$ & $\begin{array}{c}1.06 \\
(0.802)\end{array}$ & $\begin{array}{c}0.328 \\
(0.451,26)\end{array}$ \\
\hline & Q2Time & $\begin{array}{c}0.75 \\
(0.515)\end{array}$ & $\begin{array}{c}0.75 \\
(0.754)\end{array}$ & $\begin{array}{c}0.499 \\
(-0.003,26)\end{array}$ \\
\hline
\end{tabular}

Further analysis found that the time spent in the Question 1 is significantly different ( $\mathrm{p}$-value $=0.025, \mathrm{t}=2.301, \mathrm{df}=53$ ) between the two cognitive styles. Those who were classified as having field-dependent tendencies spent slightly less time than a group of field-independent tendencies.

\section{DISCUSSION}

As Dilla et al. (2010) proposing new research directions encouraging research in the venue of accounting information systems to pay more attention in the area of interactive information visualization, one of important topics is the information selection and navigation. Thus, the present study follows this research direction by attempting to explore the extent to which accounting information is searched and navigated in different patterns of tasks and decision-makers. The effects of the decision-maker characteristics, navigation strategies, and their interaction on the performance of decisionmaking were investigated by employing a quasi experiment. A web application was developed to collect data.

The results of the data analysis have shown that the decision-making performance between two cognitive styles (field-independent and field-dependent) and two navigation strategies (breadth-first and depth-first) was not statistically significantly different. Nevertheless, the time spent in the Question 1 was found to be significantly different between the two cognitive styles; field-independent and field-dependent.

Despite the fact that different navigation strategies could not be found to enhance the performance of decision-making, there is still an ample area to further investigate how information technology in information navigation could be benefit in the decision-making process.

This research is an initial step in investigating the influence of decision-maker characteristics and navigation strategies on the decision-making process. Dilla et al. (2010) had indicated the absence of literature directly addressing the topic in accounting information navigation. As a result, there were no concrete theories to help forming this research. There are various types of cognitive styles and navigation strategies. The types adopted in this research derived from the literature in the related field. Future research may consider other types of cognitive styles and navigation strategies in studying their effects on the decision-making outcomes.

\section{REFERENCES}

[1] Alles, M. G., and M. A. Vasarhelyi. 2007. The need to reengineer the business reporting process. International Journal of Disclosure \& Governance 4 (3):204-216.

[2] Chen, S. Y., and R. Macredie. 2010. Web-based interaction: A review of three important human factors. International Journal of Information Management 30 (5):379-387.

[3] Chen, S. Y., and R. D. Macredie. 2002. Cognitive styles and hypermedia navigation: development of a learning model. J. Am. Soc. Inf. Sci. Technol. 53 (1):3-15.

[4] Demski, J. S. 1980. Information analysis: Addison-Wesley Pub. Co.

[5] Dilla, W., D. J. Janvrin, and R. Raschke. 2010. Interactive data visualization: new directions for accounting information systems research.(Report). 24 (2).

[6] Feltham, G. A. 1977. Cost Aggregation: An Information Economic Analysis. Journal of Accounting Research 15 (1):42-70. 
[7] Ford, N., and S. Y. Chen. 2000. Individual differences, hypermedia navigation, and learning: an empirical study. Journal of Educational Multimedia and Hypermedia 9 (4):281-311.

[8] 2001. Matching/mismatching revisited: an empirical study of learning and teaching styles. 32 (1).

[9] Gallistel, C. R. 1990. The Organization of Learning. 1st ed ed. Cambridge, MA: MIT Press.

[10] Goldstein, K. M., and S. Blackman. 1978. Cognitive style: five approaches and relevant research. edited by S. Blackman: New York: Wiley.

[11] Harvey, D. W., J. G. Rhode, and K. A. Merchant. 1979. Accounting aggregation: user preferences and decision making. Accounting, Organizations and Society 4 (3):187-210.

[12] Lev, B. 1969. Accounting and information theory: American Accounting Association.

[13] Ohlson, J. A., and S. H. Penman. 1992. Disaggregated Accounting Data as Explanatory Variables for Returns. Journal of Accounting, Auditing \& Finance 7 (4):553-573.
[14] Otley, D. T., and F. J. B. Dias. 1982. Accounting aggregation and decision-making performance: an experimental investigation. Journal of Accounting Research 20 (1):171-188.

[15] Pedhazur, E. J., and L. P. Schmelkin. 1991. Measurement, Design, and Analysis: An Integrated Approach. Hillsdale, New Jersey: Lawrence Erlbaum Associates.

[16] Schmidt, J., and R. Spreng. 1996. A proposed model of external consumer information search. Journal of the Academy of Marketing Science 24 (3):246-256.

[17] Soliman, M. T. 2008. The Use of DuPont Analysis by Market Participants. The Accounting Review 83 (3):823-853.

[18] Witkin, H. A., D. Price-williams, M. Bertini, B. Christiansen, P. K Oltman, M. Ramirez, and J. V. Meel. 1974. Social Conformity and Psychological Differentiation. International Journal of Psychology 9 (1):11-29. 